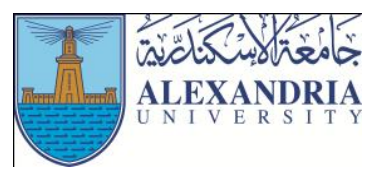

\title{
The Effect of Using Carnitine as a Dietary Supplement on Weight Loss and the Effectiveness of the Skill Performance of Boxers
}

\author{
Mustafa Mohammed Ahmed Nasr ${ }^{1}$, Ayman Mohammed Shehata ${ }^{2}$ \\ ${ }^{1}$ Assistant Professor of Athletic Training, Faculty of Physical Education, Mansoura University, Egypt; Department of Physical \\ Education and Movement Sciences, College of Education, Qassim University, Saudi Arabia \\ ${ }^{2}$ Lecturer at the Department of Health Sciences, Faculty of Physical Education, Mansoura University, Egypt
}

\begin{abstract}
:
The purpose of this study is to identify the effect of carnitine intake as a dietary supplement on weight loss and the effective performance of boxers. The experimental method was used on a random sample of boxing students in the third division of the Faculty of Physical Education - Mansoura University and registered in Dakahlia. The main research sample was (5) boxers. The food supplement was used in the final form (al-carnitine, zinc and vitamin C) during the prematch period for 4 weeks. The most important results were the use of dietary supplements - carnitine, VC, zinc) to improve the ability to lose weight. (16.1\%) and the effectiveness of defensive behavior (11.2\%) while the effectiveness of the tactical activity (13.8\%) for the sample of the study.
\end{abstract}

\section{Introduction:}

B oxing is one of the most violent individual sports because of the physical endurance A boxer is exposed to, and his desire to win, which is represented by the motor effort exerted to gain the required skills during training for the capability of performing during competing.

The physical endurance forms a huge obstacle especially when it comes to receiving powerful punches or when the opponent ins a point which other players in different sports don't experience, which leads to feeling tired easily as well as the punch received may lead to a non-direct way of passive effect on the body, thus increases the violence of this sport, in addition to what the boxer undergoes to due to weight loss which is what most boxers turn to.

Boxers compete according to weight categories to ensure justice and equal competition between players. Therefore, competing in a tournament is bound by a specific weight known as (competition weight), and it is known that some boxers had to undergo a whole seasonal training to get in shape and reach the required form but denied to participate in tours due to the failure of reaching the competition weight and had their hopes of accomplishing the desired sports dream, and so we find a lot of players have lost their shape during high level period because they failed to apply a tight plan to lose weight which led to the loss of their physical abilities and Technical skills also the failure to accomplish and results.

One of the most famous organizational rules of Boxing is Weights and every participant has the right to enroll under a eight that is limited to specific kilograms, which may lead to in most cases that a player turns to losing weight to play in a lower weight than the normal fearing to compete with a more experienced or famous player.

Therefore, losing weight is considered one of the serious problems facing Boxers in general as they were taught over the years to lose weight to participate in lower weight to gain some advantage in strength and endurance but it it affects their special result in pre-competition period.

Also, One of the serious problems that makes a boxer lose weight is overweight as if the boxer weight exceeds the limit permitted in the rules makes him opt to play in a higher weight that he will facing more obstacles in order to be able to win, so he turns to using different ways to lose weight before the competition that will decrease his competitive abilities as well as his health condition.

Losing weight by losing huge amount of water of the body may has a negative effect on the boxer as all of the kidney's functions are affected also the nervous system is endangered to stress because of the loss of Sodium ions and Chloride which prevents the boxer from continuing the match. 
Also, losing weight in a fast and wrong way effects on the capability of strength and endurance and exposes the player to be unbalanced and losing.

Once the legendary boxer Mohamed Ali Klaie and his coach that him losing $15 \mathrm{~kg}$ over a short period of time was one of the reasons of his catastrophic losing to his opponent Larry Holmes.

The researchers think that a boxer loses weight by this amount in a very short period of time is a wrong belief because it leads to a total body weakness, weaken the power of the boxer and negatively affect the level of the physical fitness as well as the health condition and efficiency level of technical performance.

On the mentioned above, Zaki Hassan 2004 refers that excessive weight loss over a short period of time could significantly disturb the performance.

The competitive performance to an athlete is the result of all physical, technical, tactical and psychological performance, so the analysis of athlete's competitive performance and it's effectiveness is considered one of the important processes that could be used to identify points of strength and weakness of a player level.

Dietary supplement is one of the alternatives that became famous as it is from natural nutrition sources and works on providing a suitable environment for muscle growth besides the special nutrition program according to the practiced sports activity also is considered one of the variable $s$ that helps lifting the players performance level and normally delay the onset of fatigue.

Dietary supplement is a substance extracted of natural nutrition component (Animal, Botanical and other substances falling within a meal) that is produced and ready in different shapes and sizes ( tablets, capsules, liquids and powders) containing the substance or the nutritional component that the athlete aims to increase its levels in the body or muscular cells to have more required energy or to increase the size of the muscular cell which depends on the specialized efficiency in order to reach high achievement level.

Samiea Khalil (2006) refers that the training loads and its doses do not meet the athlete's ambitions anymore, so the sport field is witnessing a heavy race to gain more methods to provide the aspired development with the minimal possible limit of side effects, and the lethal harms of drugs and addiction that are caused to the addict are no secret to many of whom are working in the sports field, so a lot of athletes started searching for an alternative.
Since the required goal from the losing weight process is to lose the extra weight gradually without having the training state of the player to be affected or his competitive capability with keeping his weight near the weight that he can achieve the best performance and fitness, and based on the fact that boxers use fast and extreme ways to lose weight which results a decrease in physical fitness levels, as well as cases of general weakness, decrease in strength, their punches are affected, his ability to keep balance and the sense of space on the ring and the estimation of distance between him and the rival also low levels of skill performance efficiency, and the inability to cover and the suitable defense so the boxer acts indiscriminately which exposes him to warnings, negativity and the lake of risking fearing injury so he cannot continue the match and not reaching the aspired results that fit a boxer's level in the preparation period.

Hence, a tight plan to lose weight a few weeks before the tournament is needed to avoid the harms of fast weight loss which destroys the form in an important period of the training program showing the positive adaptations of the training on the organs and tissues of the body that is called " Reaching top level" synched with pre-competitions period, and throughout the theoretical readings and the study of many studies, previous studies shows that there are many studies on weight loss but, none of which have discussed the issue of the effect of taking carnitine as a dietary supplement on weight loss and the effectiveness of skill performance of boxers which led the researchers to choose this issue to be the subject of research and experiment. So this study objective is to identify the effect of taking carnitine as a dietary supplement on weight loss and the effectiveness of skill performance of boxers, While hypotheses are that eat Carnitine affects weight loss of boxers. And on the effectiveness of the Aggressive behavior and the effectiveness of the defensive behavior and the effectiveness of the tactical activity of the study group.

\section{Procedures:}

- The Research Method: Experimental Method Using Experimental Design for One Set and Pre-Post measurement.

- Spatial Field: The boxing hall at the Faculty of Physical Education, Mansoura University.

- Time Domain: The pre, sequential and post measurements were carried out and the training program was applied during the pre-tournament period as part of a special training program for boxing players from $6 / 7 / 2016$ to $7 / 8 / 2016$. 
- Study Group: The research sample was chosen by the intentional method of the students of boxing major in the third division at Faculty of Physical Education - Mansoura University and registered in the Dakahlia boxing area, number of (5) students

\section{Measurements and Testing:}

- Basic Measurements: (Age- Height-Weight- the Training Age).

- Battery of Measuring the Fitness Components of Boxers prepared by Ismail Hamed et al. 2002 (2), consisting of five tests performed in one day, and it was considered to be applied in the same sequence. Annex 4 .

- Performance Endurance Test: Hitting the right and left straight punches of the head on the various punching devices.
- Skill Performance Test: the efficiency coefficient of the skill performance.

\section{Devices and Tools:}

Restameter for measurement of height and weight in centimeter

- Stopwatch (.01 second)

- Boxing gloves, punching bags, bounce ropes, bounce balls, Wall pillow, Boxing ring

- Personal player registration form and tests

- The Coefficient of effectiveness of skill performance is outlined through the usage of a video recording device and analysis (VCR - 225) Panasonic Video Tape Recorder.

Table (1)

Statistical Characterization of the Research Sample $(n=5)$

\begin{tabular}{|c|c|c|c|c|c|c|}
\hline \multirow{2}{*}{\multicolumn{2}{|c|}{ Variable }} & \multirow{3}{*}{$\begin{array}{c}\text { Measurement Tools } \\
\text { Year }\end{array}$} & \multicolumn{4}{|c|}{ Experimental group } \\
\hline & & & \multirow{2}{*}{$\begin{array}{c}\text { Average } \\
20.6\end{array}$} & \multirow{2}{*}{$\frac{\text { Median }}{2.07}$} & \multirow{2}{*}{$\begin{array}{c}\begin{array}{r}\text { Standard } \\
\text { Deviation }\end{array} \\
21\end{array}$} & \multirow{2}{*}{$\begin{array}{r}\text { Skewnes } \\
-0.236\end{array}$} \\
\hline 1 & Age & & & & & \\
\hline 2 & Height & $\mathrm{CM}$ & 173 & 7.9 & 171 & 0.61 \\
\hline 3 & Weight & KGM & 71.6 & 71.2 & 0.865 & 1.526 \\
\hline 4 & Training Age & Year & 7 & 1.87 & 8 & -0.38 \\
\hline 5 & Sit down from supine for $30 \mathrm{sec}$. & Number & 26.8 & 27 & 0.837 & -0.717 \\
\hline 6 & Side steps & Number & 23.2 & 23 & 0.447 & 1.342 \\
\hline 7 & Wide jump from stability & $\mathrm{CM}$ & 190.6 & 190 & 2.608 & 0.690 \\
\hline 8 & Tensile on the horizontal bar for $30 \mathrm{sec}$. & Number & 8.8 & 9 & 0.836 & -0.717 \\
\hline 9 & $\begin{array}{l}\text { Sit on four tossing the two legs behind } \\
\text { in } 30 \mathrm{sec} \text {. }\end{array}$ & Number & 17.6 & 18 & 0.548 & -2.190 \\
\hline
\end{tabular}

Table 1 Shows that the Skew-ness value for the special measurements of the characterization of research sample ranged between $(-0.760 \cdot 0.629)$ and that values was limited between $-3 a+3$ which Indicates the moderation of the values of the research group before the experiment.

\section{Components of the Supplement:}

Through the researchers study of many references, scientific research and relative studies that discussed Carnitine, It shows that there was an agreement on the necessity of adding extra anti-oxidants to the Carnitine as Vitamins or minerals in order to avoid Secondary lipid oxidation products, the two researchers chose (Vitamin C, Zinc) and the final form of the supplement used is (Carnitine, Vitamin C, Zinc).

\section{Dosing:}

It showed -after the study of relative studies and scientific references that the used doses for athletes are between (1-2 gm/day). Therefore, the researchers proposed that the supplement on its final form should be (Carnitine, Zinc, and Vitamin C) to be as follows:

- $2000 \mathrm{ml} . \mathrm{gm}$ of Carnitine per day over two doses each is $1000 \mathrm{ml} . \mathrm{gm}$.

- $34.14 \mathrm{ml}$. gm Zinc per day over two doses each are equal to $17.7 \mathrm{ml}$. gm.

- $500 \mathrm{ml} . \mathrm{gm}$ of Vitamin C per day.

\section{Pre-Measurements:}

The pre measurements were conducted during 6-7/7/2016 at the Boxing hall at Faculty of Sports and Physical Education in Mansoura University.

\section{Conducting the basic Study:}

The basic study took place from 9/7/2016 until 5/8/2016 as the following: 
1- Capsules Containing Carnitine (1000 ml.gm, Zinc 17.7 ml.gm) Vitamin C capsules 500 ml. gm).

2- The capsules were given the players.

3- The use dose consisted of 2 capsules/day Carnitine after breakfast and 1 capsule/day Vitamin $\mathrm{C}$ after dinner for 4 weeks

4- A dietary program for each player separately. Annex 6.

5- Training program: the training program was applied for one month in the pre-competition period in at the Boxing hall at faculty of Sports and Physical Education Mansoura University with 4 units per week.
6- Weight Measurement Phase 3 times during experiment at the end of every week of taking the supplement and the training units.

\section{Post measurements:}

The post measurements were carried out after the end of application of the training program on the study group subjects during 6-7/8/2016 according to the pre measurement.

\section{Statistical Process:}

(The Arithmetic Average- Wilcoxon Test- Equation of Improvement Ratios)

Results and Discussion:

Table (2)

Arithmetic average, standard deviation and improvement ratios of measurements for the four weight measurements of the experimental group

\begin{tabular}{|c|c|c|c|c|c|c|}
\hline \multirow{2}{*}{ Variable } & \multirow{2}{*}{ Measurement } & \multirow{2}{*}{ Average } & \multirow{2}{*}{$\begin{array}{l}\text { Standard } \\
\text { Deviation }\end{array}$} & \multicolumn{3}{|c|}{ Improvement Ratios \% } \\
\hline & & & & Second & Third & Fourth \\
\hline \multirow{4}{*}{ Weight } & First & 71.64 & 0.865 & 3.1 & 6.6 & 9.7 \\
\hline & Second & 69.44 & 0.288 & & 4.0 & 6.9 \\
\hline & Third & 66.88 & 0.164 & & & 3.0 \\
\hline & Fourth & 64.66 & 0.182 & & & \\
\hline
\end{tabular}

Figure (1)

shows the arithmetic of the four weight measurements of the experimental group

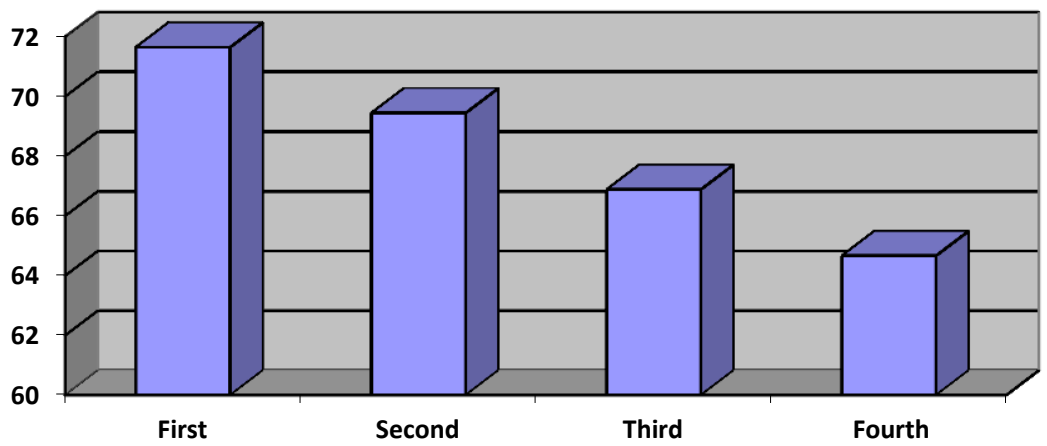

口Weight Measurements 
Table (3)

Significance of the differences between the median of the experimental pre measurements of the experimental group in the effectiveness of the skill performance $(n=50)$

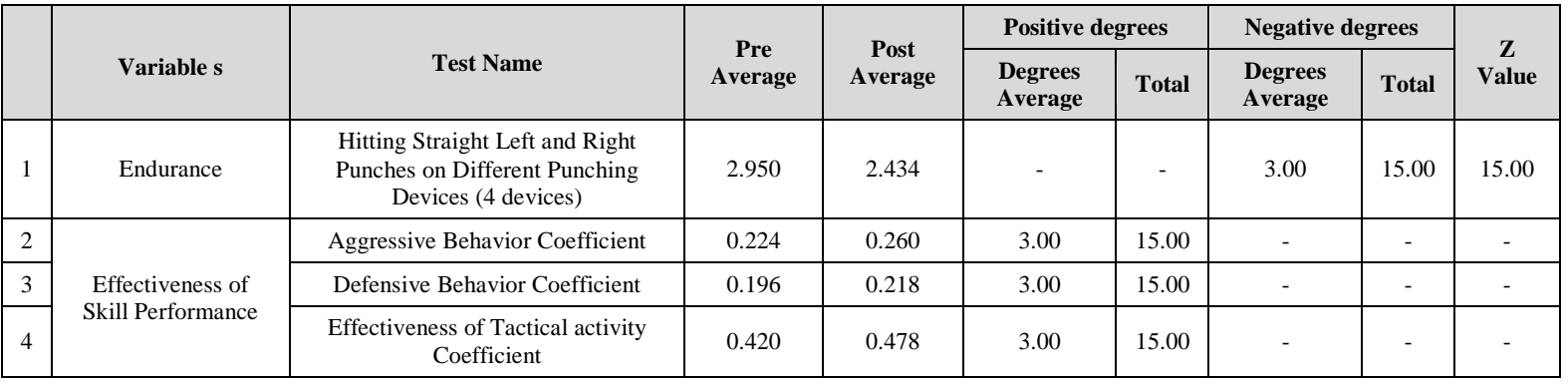

$*$ The value of $(\mathrm{Z})$ of the scale is at level $0.05=+1.96$

Table (3) shows that there are statistically significant differences between the averages of the pre- and postmeasurements of the experimental group in favor of the post measurement at the level of (0.05) in the performance endurance tests, the aggressive and defensive behavior coefficient, and the coefficient of the tactical activity, and that is what confirmed by $\mathrm{Z}$ of the scale.

Table (4)

Percentage of improvement of the experimental group for the level of effectiveness of the skill performance

\begin{tabular}{|c|c|c|c|c|c|c|}
\hline & Variable s & Test Name & $\begin{array}{c}\text { Pre Measurement } \\
\mathbf{x}\end{array}$ & $\begin{array}{c}\text { Post Measurements } \\
\mathbf{X}\end{array}$ & $\begin{array}{c}\text { The average } \\
\text { difference }\end{array}$ & $\begin{array}{c}\text { Percentage } \\
\%\end{array}$ \\
\hline \multirow{2}{*}{1} & Endurance & $\begin{array}{c}\text { Hitting Straight Left and Right } \\
\text { Punches on Different Punching } \\
\text { Devices (4 devices) }\end{array}$ & 2.950 & 2.434 & 0.516 & 17.5 \\
\hline \multirow{2}{*}{2} & \multirow{2}{*}{$\begin{array}{c}\text { Effectiveness of } \\
\text { the skill } \\
\text { performance }\end{array}$} & Aggressive Behavior Coefficient & 0.224 & 0.260 & 0.036 & 16.1 \\
\cline { 3 - 8 } & Defensive Behavior Coefficient & 0.196 & 0.218 & 0.022 & 11.2 \\
\cline { 2 - 8 } & $\begin{array}{c}\text { Effectiveness of Tactical activity } \\
\text { Coefficient }\end{array}$ & 0.420 & 0.478 & 0.058 & 13.8 \\
\hline
\end{tabular}

Table (4) shows that the highest percentage of improvement was for the endurance behavior (17.5\%) and the lowest percentage of improvement was the defensive behavior (11.2\%).

Figure (2)

The significance of the differences between the mean and the remote measurement of the experimental group of tolerance and the coefficient of the efficiency of the skill performance

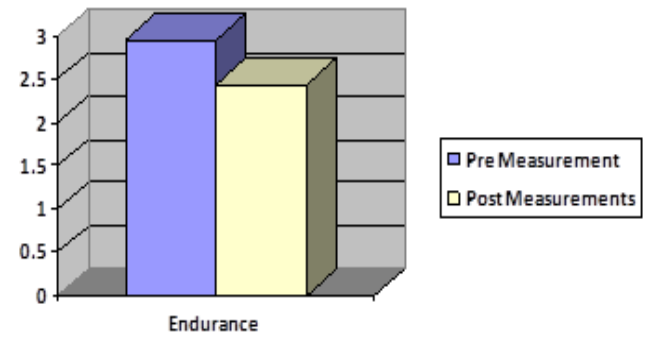

\section{Discussion:}

Table 2 and figure 1 show significant differences in the weight variable in favor of post and consecutive measurements at a significant level of 0.05 where the average of the second measurement was (44.69) and the

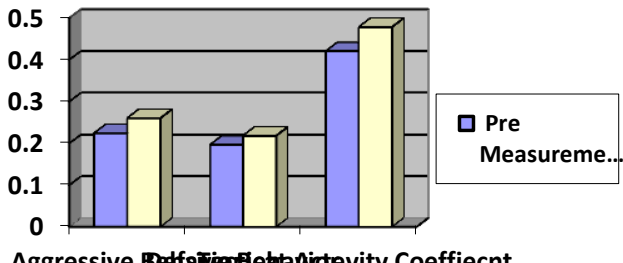

Aggressive BuffaTitentehinaictevity Coeffiecnt

third (88.66) whereas the fourth was (66.64) which is thought to be due to the positive effect of the usage of the supplement Carnitine at its final form which had been taken during pre-competition period of the study group, which goes hand in hand with the results of both of Manal Talaat Muhammed (2008) on decreasing fat percentage for 
the ladies after using Carnitine as a dietary supplement. and the results of Rupert et al (2004) that Carnitine is considered one of the most important supplements used in weight loss as it works on shaking the fats and the process of oxidation it and acquiring energy, also the results of Meriam Karimi et al (2016) that using Carnitine as a dietary supplement led to reducing the percentage of fats inside the body Thus weight loss.

This is confirmed by the percentage of improvement where it was between the second and first measurements (3.1\%), the third and the second (4.0\%), the fourth and the third (3.0\%). This is consistent with what was referred to by Massad Mahmoud 1981 that the body should be reduced within $5 \%$ to $7 \%$ of body weight.

Cruciani et al. (2015), Brass (2004), states that the role of carnitine is to move fat into the mitochondria where it is oxidized and obtained as energy, resulting in weight loss for the consumption of fat.

The results of this study agree with the findings of Uchendu et al (2011) that the relationship between the ability of carnitine supplementation to oxidize fat to provide energy and thus lower percentages of fat and weight loss.

Table (3), (4) and (2) shows significant differences in favor of post-measurement at level of (0.05) in the Endurance test under study and the effectiveness of the skill performance (the behavior of the aggressive; behavior) where the value of $(\mathrm{Z})$ favoritism was higher than its tabular value $( \pm 1.96)$ at a significant level of 0.05 . The average Endurance test (2.434) with a percentage increase $(17.5 \%)$, average aggressive behavior $(0.260)$ percentage (16.1), average defense behavior $(0.218)$ percentage $(11.2 \%)$ and average tactical activity $(0.478)$ This is what the researchers believe to be due to the positive effect of the dietary supplement and the training program which depends on the continues training as well as taking the dietary supplement carnitine on a regular basis while continuing the training.

This is in line with what Meriam Karimi et al (2016) pointed out that taking carnitine has a significant effect on body fat and weight loss. After four weeks of training.

According to Mosaad Mahmoud (1981), ,citing Bogert et al. (1972), that weight loss using a combination of food as well as physical activity accelerates weight loss, increases physical fitness, and protects tissues from loss of fat. As Williams, M, and H (1976) also pointed out that the method of feeding and exercising is an effective way to lose weight. In this way we can obtain a desirable modification in body composition and decrease the percentage of fat.

The results of the study are also in line with what the American College of Sports Medicine (ACSM) has indicated to lose weight in eating adequate amounts of vitamins and minerals, as well as to benefit from the positive effect of exercise on fat elimination and improving fitness.

\section{Conclusions:}

By presenting and discussing the results, the following conclusions were reached:

- The use of the dietary supplement components (AlCarnitine, VC, zinc) led to improve the ability to lose weight for boxers study group.

- The use of the dietary supplement improved the effectiveness of skill performance by developing aggressive behavior $(16.1 \%)$ and the effectiveness of defensive behavior $(11.2 \%)$ while the effectiveness of the tactical activity was $(13.8 \%)$ of the sample of the study.

\section{Recommendations:}

In light of the findings of the research findings, the researcher is recommended to:

- Use of the dietary supplement ingredients (Al-carnitine, $\mathrm{VC}$, zinc) with training programs for boxing players because of its effectiveness in weight loss for boxers during the pre-competition period.

- Weight loss is within 5 to $7 \%$ of body weight, depending on the percentage of body fat.

- A weight loss plan should be applied in a gradual manner before the competition from 3 to 4 weeks.

- Study the effect of different types of dietary supplements and conduct comparative studies among them to identify their impact on different physical and skill variables on athletes.

\section{References:}

1- Abdel-Fattah F, Khader (1996) : The Reference in boxing, Almaaref, Alexandria. P.181(In Arabic)

2- Abu Ela Ahmed Abdel Fattah (1997) : sports training and physiological bases , Dar Elfekr Elarabi, Cairo . pp.26 (In Arabic)

3- Bahaa Al-dean M, Salama (2000): Food Health and Organs safety, AlFekr Al-Arabi House, Cairo,. pp 36(In Arabic) 
4- Brass EP(2004) : Carnitine and sports medicine: use or abuse? Ann NY Acad Sci;1033: pp (67-78).

5- Eisaman .A .Patricia, (1998) : Coasches Guide to natrition and Weight Control, second edition, university of Utah champaign ,illnois. pp102(In Arabic)

6- Ismail Hamid, Mohamed A, Ghoneim, Diaa Eddin Azab, Atef Mgaroy (2002) : Boxing (education, training and management), Dar Al Sadaa, Cairo. pp 49(In Arabic)

7- Cruciani RA, Revuelta M, Dvorkin E, Homel P, Lesage P, Esteban-Cruciani N(2015): L-carnitine supplementation in patients with HIV/AIDS and fatigue:Center for Comprehensive Pain Management and Palliative Care, Capital Institute for Neurosciences, Capital Health Medical Center, Pennington, NJ, USA. pp 33

8- Fogelhalm , Mikael,(1994): Effect of body weight reduction on sports performance department of applied chemistry and microbiology university of helsiki Finland. Sports Med Oct;18(4):249-67.

9- Finkenberg, Mel E; DiNucci, James M; McCune, $E(1992)$ : Analysis of the effect of competitive trait anxiety performance in teakwondo competition, journal of percept motor skills, Missoula Mont,. . pp (239 - 243)

10- Giuseppe D’Antona,( 2013) : Nutritional Interventions as Potential Strategy to Minimize Exercise-Induced Muscle Injuries in Sports, http://dx.doi.org/10.5772/56590,.

11- Hagen TM, Liu J, Lykkesfeldt J, Wehr CM, Ingersoll RT, Vinarsky .etch(2002): Feeding acetyl-L-carnitine and lipoic acid to old rats significantly improves metabolic function while decreasing oxidative stress. Proc Natl Acad Sci; 99:1870-5. USA

12- Heidrun Karlic, Alfred Lohninger,( 2004) : Supplementation of L-Carnitine in Athletes: Does It Make Sense? Institute for Leukemia Research and Hematology, Vienna, Austria; and the Department of Medical Chemistry, University of Vienna, , pp 94

13- Hussien A, Heshmat (1999): Biological and biochemical techniques and their applications in the field of sport, 1st Edition, universities, publication house, Cairo. pp 50 (In Arabic)

14- Manal T, Muhammed (2008) : Effect of aerobic exercise and Carnitine on improving athletic performance, blood lipids and some body measurements for women aged 45-50",unpublished PhD thesis, Faculty of Physical Education for Girls, Helwan University, Cairo,. pp 66 (In Arabic)

15- Maryam Karimi, Ebrahim Karimi, Sepideh Mizani, ( 2016): The Effect of Four Weeks Hiit TrainingWith The Use of L-Carnttine on Fat Percent ofTrained Overweight Women, European Journal of Physical Education and Sport Science, Volume 2 , Issue 1. ISSN-L: 2501 - 1235,

16- Mousaad Ali Mahmoud(1981) : Effect of different ways to lose weight Endurance league respiratory and muscular endurance of the wrestler, Ph.D. unpublished, Faculty of Physical Education for Boys, Alexandria University,. pp 160 (In Arabic)

17- Mostafa .A., Nasr ((2007)) : Effect of Training Program of Physical Complicated Qualities on Some Physiological Variables and Effectiveness of skillful Performance of young boxers. Ph.D. Thesis, Faculty of Physical Education, Mansoura University, Egypt.pp 42(In Arabic)

18- Nasr A, B, Nasr (1993): Effect of weight loss on the concentration of saline sodium and potassium in the blood of wrestlers, unpublished master thesis, Faculty of Physical Education for Boys, Helwan University.. pp 14 (In Arabic)

19- ROBERT B. SAPER, M.D., M.P.H., DAVID M. EISENBERG, M.D., and RUSSELL S. PHILLIPS, M.D. (2004): Common Dietary Supplements for Weight Loss, Am Fam Physician. Nov 1;70(9):1731-1738.

20- Samea Khalil Muhammed, (2006): Dietary supplements as an alternativeto steroids, College of Physical Education for Girls, Baghdad University pp 35 (In Arabic)

21- Uchendu Chidiebere, Suleiman F Ambali, Joseph O Ayo and King A N Eseivo. (2011): Acetyl-L-carnitine attenuates haemotoxicity induced by subacute chlorpyrifos exposure in Wistar rats. Der Pharmacia Lettre. 3(2):292303.

22- Zaki Muhammed Hassan(2004) : False beliefs and habits in the nutrition of athletes, the sports series, the Egyptian Library, Alexandria.

23- http://www.acsm.org/ 